\title{
Innovating a Business Model for Services with Storytelling
}

\author{
Morten Lund \\ Center for Industrial Production, Aalborg University \\ ml@business.aau. dk
}

\begin{abstract}
In recent years, the notion of business models has been able to innovate the way companies create new business opportunities. However, because business models most often rest on a complex interplay of several actors, there is a need to be able to explore the nature of a business model.

This paper will propose to describe a business model by means of storytelling. Also, the paper will introduce the notion of archetypes of business models with the aim to seek a pattern in the light of the numerous business models available. Two cases will illustrate and discuss storytelling and archetypes, giving rise to conclude that they represent a valuable approach to understanding and innovating business models.
\end{abstract}

Keywords: Business models, Free-business models, narratives, storytelling, business model innovation, archetypes.

\section{Introduction}

The growing interest in understanding and innovating business models in recent years is most likely a result of an increased recognition that a successful business model can be a game changing factor in competition or in entering a new market. However, as a novel concept, many questions arise of both theoretical and practical nature. To explore some of these issues, a Danish research program "ICI" was initiated aimed to inspire and assist participants in a development process of innovating new global business models in a network of smaller, traditional industrial companies and new ebusiness companies. The research program has shown that a novel approach is needed to illustrate how a new business model may look, especially to provide a picture of an emerging business model that can persuade interested parties what they may gain and which role they would be supposed to play. We have experienced that storytelling represents a fruitful approach which we intend to discuss in this paper.

Furthermore, both practice and theory include quite a large number of different business models. This has led us to explore if patterns may be identified by way of the notion of business model archetypes. From the research program we have selected two related cases that will illustrate elements of storytelling. In addition, they will form a basis for discussing the notion of archetypes that will also be illustrated by existing business models. In this paper, we shall first introduce the notion of business models, storytelling and archetypes. Then the two cases will be presented, followed by a discussion. Finally, the paper will be concluded. 


\subsection{Business Models}

Business model theory as a separate research area is relatively young. Until 2000, the notion of business models was largely related to the preserve of internet-based businesses [Mason 2011]. But since then, research on business models has intensified accompanied by an escalating quantity of literature from both practitioners and academia. The area of business models is thus still young and also quite dispersed. The field as a stand-alone is just starting to make inroads into top management journals, but the conceptual base is still thin [Zott, Amit \& Massa 2011].

The definition of the term business model has been discussed substantially over the last decade. From a simple definition, e.g. "Business model is a statement of how a firm will make money and sustain its profit stream over time" [Zhao 2010] to definitions including partners or stakeholders, e.g. "A conceptual tool that contains a set of elements and their relationships and allows expressing the business logic of a specific firm. It is a description of the value that a company offers to one or several segments of customers and the architecture of the firm and its network of partners for creating, marketing and delivering this value and relationship capital, to generate profitable and sustainable revenue stream" [Osterwalder et al., 2004]

We have come to the conclusion that a business model is too multifaceted to be defined in any simplistic way. Overall, a business model consists of two elements; what the business does, and the way in which the business gains profit.

There have been attempts to describe business models as systems consisting of a variation of building blocks, e.g. the Business Model Canvas [Osterwalder XXXX], which describes a business model by means of nine interrelated building blocks. Osterwalder's work has provided a popular framework for describing, understanding and innovating business models for a company. The framework has been used successfully in our research program but has also shown limitations. We have found that several companies and individuals can be considered actors forming a network in a new business model. There is a need to develop a framework for each partner [stakeholder] and for the network as a whole. Another limitation is the static nature of the business model canvas, in view of the desire to generate new ideas.

\subsection{Storytelling}

Storytelling exists throughout all cultures and is an inevitable part of human communication and interaction. Stories can pass on accumulated knowledge, ideas, and values, as for example used in anthropology. Through stories we are creating a narrative image of constructions enabling us to explain complex things, for example proposed as part of corporate strategy development, Kotter [1990], Riis \& Johansen [2003]. In this paper narratives and stories are treated as synonyms, ignoring the semantic discussion on the distinction between narrative and storytelling.

Magretta [2002] gained considerable attention by identifying business models as "stories that explain how enterprises work". According to Magretta, business models did not only show how the firm made money but also answered fundamental questions such as: "who is the customer? and "what does the customer value?" 
In comparison to a traditional strategy statement, a story is told focusing on what actors do and through such a process description it is explained how money, information and goods and services flow between actors, including customers. In this way, it becomes clear to actors what their role will be, as well as their expected benefits and obligations.

In our research program we have learned that a story evolves through interaction with actors, as they contribute with ideas and own experience and express their preferences. Furthermore, a story can be told in many different ways. On the one hand, it is important to be open for new and innovative ways of expressing a story; on the other hand, we should seek generic elements or questions expected to be addressed in a story.

We found that storytelling may be an important approach for developing a business model in a network of companies and individuals with different backgrounds and qualifications. The process of developing a story serves as a platform for a constructive dialogue for combining different opinions into a coherent business model.

\subsection{Archetypes}

The notion of archetypes represents an attempt to identify generic patterns or classes that may be used as inspiration for developing a specific business model.

Although it is desirable to develop archetypes for successful business models, there is no single, well-defined classification of business model archetypes in the literature. Osterwalder applies the term pattern as an expression that comes from the world of architecture. I his use of the term it stands for the idea of capturing architectural design ideas as archetypal and reusable descriptions.

One may argue that patterns can be formed at a macro and a micro level in an industry or a business. The macro level of business models archetype may express roles in an industry, e.g. wholesaler, consultants, distributor, production, banks, etc. They show how corporations interact with stakeholders of their business model in distinct patterns. For example, Miles \& Snow [1978] showed how companies could exists side by side in an industry [books for the educational market] with generic different business models. The macro level business models may consist of variations in patterns. For example, differences between a supermarket and a food wholesale basically lie in the costumer segment. Although the basic business model of "primarily selling products manufactured by others" and the revenue models seem to be alike, only differentiated by quantity and assortment, the two business models are very different. The relationship with suppliers [stakeholders in the business model] is different. In the wholesale business model, suppliers often have relations directly with the customers, discussing price, exclusivity etc. The cost structure is different based on the average turnover per customer. These are examples of small variations in business models at the micro level.

Focusing on micro level business models enables development of specific archetypes of business models describing typical patterns in one or more interrelated building blocks of a business model. As an example, Anderson [2009] presents four 
revenue model archetypes. He explores how things can be "Free" implying how a product may be provided for free, yet still supporting a viable business model. Sometimes "free" is not really free. "Buy one, get one for free" is just another way of saving 50 per cent off when you buy two. "Free gift inside" really means that the cost of the gift has been included in the overall product. "Free shipping" typically means that the price of shipping has been built into the product's markup. He defines the Free business model as cross-subsidies essentially based on the phrase "there's no such thing as a free lunch." This means that one way or another the food must be paid for, if not by you directly then by someone else whose interest it is to give you free food. Andersen demonstrates that there are different "Free business models archetypes".

Within the broad world of cross-subsidies, Andersen describes four main categories or archtypes. One of the archetypes is "Freemium", a common revenue model on the Internet. It can be described as a revenue model where $5 \%$ of the customers pays for $95 \%$, e.g. Skype. The reason for this model to function is that the cost of a Skype customer is close to nothing, and the revenue on the $5 \%$ is enough to cover the operation cost. In this example the revenue model archetype provides universally understood pattern enabling us to ask the question "could your business adopt this cost structure?"

This classification focuses on the value paid by customers. Based on our research, this represents an important dimension for identifying archetypes of business models. Other dimensions may be added, e.g. from the Business Model Canvas.

\section{Two Case Companies}

\subsection{Methodology}

Two comparative case studies will be presented aimed to illustrate the notion of storytelling and archetypes. The first case study is based on a longitudinal in-depth qualitative case study over a period of two and a half years of a Danish start-up in the media industry, C-Spot. The network of companies and individuals behind C-Spot developed a clever business model for outdoor advertising through a new IT platform. The second case study is based on interviews and a workshop in the global industrial enterprise, Otis Elevator Company.The longitudinal study of Cspot was an interventionist research project [Lukka 2005]. Our research group followed CSpot from before the company was founded until now, involving the founders, the CEO and senior staff from the company, as well as four business partners, consultants and researchers. The project had a defined goal to invent a new global business model for the company. During the research project, there have been numerous meetings, workshops, reports and semi-structured interviews, which are recorded and/or documented with minutes, pictures or video. The terminology of the business model was introduced to all participants, and especially the use of the Business Model Canvas [Osterwalder 200x], and narratives exemplifying existing, successful business models. The second case study, Otis, is based on semi-structured interviews and a workshop. The semi-structured interviews were conducted with a senior sales 
manager from the Danish division of Otis. Background information on the Danish elevator industry is based on semi-structured interviews with three industry professionals, statistics and data from official public databases. CSpot is a Danish start-up company, founded in 2009. The business idea was to establish a new advertising channel consisting of a network of physical advertising screens in shop windows set up in areas with a high frequency of pedestrian traffic and showing a constant flow of live messages. The idea of CSpot originated from an idea of using all the empty shop windows that increased in numbers as a result of the financial crisis, but it quickly became apparent that existing shops were just as interested. The screens are connected by a genius virtual platform offering inexpensive advertising opportunities at affordable prices targeting small and local businesses as well as large campaigns. The business model success is based on a radically different cost structure and at the same time a new value proposition to advertisers. Compared to existing advertising channels, the CSpot's channel is different in many ways; e.g. their key value proposition is instant advertising. Usually, e.g. at AFA JCDecaux and Clear Channel, marketing has to plan ahead, produce posters, distribute and put them up. With the Cspot system, advertisers simply go to their website. Here, advertisers choose where and when to show their campaign. Either the advertiser uploads existing material or uses the free online spot builder. This enables customers to advertise instantly and relevant. For example, a local restaurant could put out an offer, if it is a slow night, or if the weather turns to rain. The local department store can attract customers with an attractive offer. The cost structure is also different. In addition to the obvious savings from production and distribution cost of a static media, CSpot came up with a clever model, reducing infrastructure cost drastically. The competitors like AFA JCDecaux and Clear Channel have great costs placing their billboards on house ends or by paying for public exterior. CSpot managed to attract more than 100 sites based on the model: your window space and power in exchange for a quantity of free advertising on the system in your local area. In fact the only cost for Cspot is setting up the screen, maintenance and the GSM Internet connection. Despite the immediate success in creating a good business model, it was difficult to attract large advertisers that often are managed by advertising agencies. The main reason for this is lack of documentation of the effect and the number of people who view the screens. A solution was discussed to install surveillance in every CSpot, providing automatic counting. But the investment was simply too high. The Otis Elevator Company is the worlds largest manufacturer of elevators and escalators. The Danish branch's business model is a typical "service business" where the key activities are to install, modernize and perform services on elevators, escalators and moving walkways. The key resources are knowhow, skilled employees and access to spare parts and tools from the main company. The Danish elevator industry seems to be segmented into two types of businesses. The global actors that are present nationally and local/regional actors. The global actors such as Otis, Thyssen-Krupps, Schindler and Kone all seem to follow the same "services business model" as described. The local actors primarily focus on service and renovation of existing installed elevators, a few on new elevators. From interviews with industry professionals including the case company Otis, they all seemed to agree that the business is all about the services contracts. It is well known in the industry that the global actors often sell new elevators near cost prices, making money on the service. 


\section{Empirical Discussion}

The two cases represent different situations with respect to innovating a business model. The first case, CSpot, developed a new idea from scratch by a few core members of a network that was gradually expanded as the business model emerged. The second case, OTIS, took the existing business model as point of departure and sought to expand it by augmenting new activities, new actors, and new revenue models.

In this section we shall discuss how storytelling and the notion of archetypes were used in the process of developing an innovative business case, and in particular discuss some of the challenges experienced. It is interesting to note that the second case was originated as an offspring of the first case. The cases serve multiple purposes; primarily to introduce various principles of applying a storytelling approach that may give rise to conclude that they represent a valuable approach to understanding and innovating business models. Second, to show how two business models can be merged in a complimenting business model.

\subsection{Using Storytelling to Tackle Business Model Challenges}

The CSpot case emerged as a trial-and-error, explorative process with many themes being addressed simultaneously. It was difficult to find a common revenue model that could demonstrate the benefit to investors and customers. Two approaches were tried. Inspired by the Osterwalder Business Model Canvas, the notion of storytelling was introduced as a means of combining different ideas into a story telling what would take place when a service is offered, and how actors would interact.

The second approach was to be inspired by existing, successful business models. In the CSpot case, the story of Google's business model served to understand new facets of a business model, in particular to use knowledge about users as an asset. For example, Google uses the location of users when a search is made, providing a more relevant link between customers and advertisers. This generates additional income, because search becomes more effective.

This story inspired the development of a business model in the CSpot case. For example, how could CSpot location data create additional value for advertisers and also generate more revenue for CSpot, and how could CSpot provide value to users so they would interact with spots. This led to the idea of getting users to take a picture with their smartphone, and to provide spots with 2D barcodes opening for virtual connection to customers. As a result, a new revenue model emerged where advertisers would pay a provision if they get a customer. At the same time, it created a potential relationship to customers with new business opportunities.

The story of Google generated many questions that served as a vehicle for a structured process of understanding the challenges and potentials of the CSpot business model, and of developing a story of an innovative business model. This also proved useful when new spot partners were introduced during the process.

At the end of the development of the CSpot business model, an idea came up that elevators were a perfect place for a CSpot because of the attention you have from 
people using an elevator and the knowledge it is possible to generate about their background and interests. As a result, it was decided to contact the OTIS company for an explorative discussion.

\subsection{Why Should Otis Implement CSpots in Elevators?}

The Danish branch of Otis has a clear business model that may be defined at a macro level as a "services business model". The revenue of the company is among the best in the industry, and the company has a substantial market share and track record. All in all, the business model seems to be working, and Otis profits from this. Why should Otis implement CSpots in elevators? Or could the question be rephrased: why should Otis add a new business model or change an existing that is working.

At a workshop, an Osterwalder Business Model Canvas was created identifying the existing business model. It revealed that customers were unlikely to pay more for the service of Otis. How could this be addressed? Based on the archetypes introduced by Anderson [2009], the facilitator introduced several existing business models of offering services or products for free. This generated a constructive dialogue on how installation of CSpots in elevators could create revenue for both the owner of an elevator and Otis. Otis showed great interest in different cross-subsidies models, e.g. CSpot paying for the service in exchange for advertising space, enabling Otis to offer Free service to their customers. During the workshop the facilitator introduced the "business model questions" used in the CSpot Case. This enabled validation on the integration between two business models. E.g. the technology present in Otis elevators offers different value proportions to the CSpot business model. Otis elevators can count passengers based on a weight average and count the numbers of trips. This providing advertisers with more accurate data, increasing profit for CSpot. Although not yet implemented, the workshop showed that innovation of an existing business model may be facilitated by use of existing, successful business models organized in a spectrum of archetypes ensuring a broad explorative process.

\section{Conclusion}

In view of the complex interplay of several actors forming a business model, this paper has discussed the idea of describing a business model by means of storytelling, explaining how the interplay of enterprises works to generate value for customers as well as partners. Two case studies illustrated how storytelling could serve as a means of combining different ideas and perspectives into a unified presentation of a business model. Also the story of existing, successful business models may serve as a vehicle for an innovative, collaborative process with many actors.

The notion of archetypes was introduced to inspire a broad innovative process. We chose to focus on revenue models and presented and used a special category under the heading "Free service". In the Otis case, this provided a new way of looking at the existing business model. However, there is a need to further explore the notion of archetypes, for example to identify other revenue models and to introduce other 
dimensions of a classification. A pragmatic approach would be to use existing successful business models as a basis for identifying patterns and classes.

The emerging area of business models has been able to innovate the way companies create new business opportunities. However, many challenges arise in connection with working in practice with business models. This paper has pointed to new directions of carrying out a collaborative process involving several actors by introducing the notion of storytelling and archetypes and by showing how they may serve as vehicles for creating an overall image combining different ideas and viewpoints.

\section{References}

Anderson, C.: Free, the future of radical price. Random House (2009)

Osterwalder, A., Pigneur, Y.: Towards Business and Information Systems Fit through a BMO. Working paper, Ecole des HEC. University of Lausanne (2003)

Osterwalder, et al.: Business Model Generation: A Handbook for Visionaries, Game Changers, and Challengers. John Wiley (2010)

Osterwalder, A.: An e-Business Model Ontology for the Creation of New Management Software Tools and IS Requirement Engineering. Working paper, Ecole des HEC, University of Lausanne

Lukka, K.: Approaches to case research in management accounting: the nature of empirical interventio and theory lunkage. In: Jönsson, S., Mouritsen, J. (eds.) Accounting in Scandinavia - The Northern Lights. Stockholm, pp. 375-399. Copenhagen Business School Press, Copenhagen (2005)

Mason, K., Spring, M.: The sites and practices of business models. Industrial Marketing Management 40, 1032-1041 (2011)

Magretta, J.: Why Business Models Matter. In: HBR, pp. 3-8 (May 2002)

Miles, R.E., Snow, C.C.: Organizational Strategy, Structure and Process. McGraw-Hill, New York (1978)

Morris, M., Schmindehutte, M., Allen, J.: The entrepreneur's business model: Toward a unified perspective. JBR 58(6), 726-735 (2003)

Kotter, J.P.: A force for change: How leadership differs from management. The Free Press (1990)

Riis, J.O., Johansen, J.: Developing a manufacturing vision. Production Planning and Control 14(4), 327-337 (2003)

Stewart, D.W., Zhao, Q.: Internet marketing, business models, and public policy. Journal of Public Policy 19, 287-296 (Fall 2000)

Zott, Amit, Massa: The Business Model: Recent Developments and Future Research. Journal of Management 37 (2011); 1019 originally published online (May 2, 2011) 